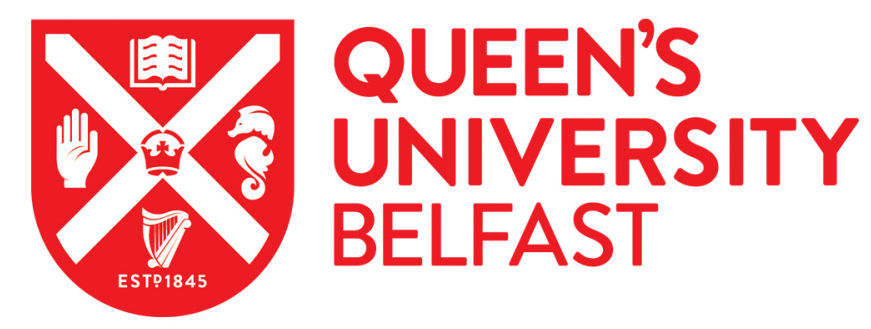

\title{
Applications of Mechanochemistry for the Synthesis of DNA on lonic Liquid Supports
}

Johnston, C., Hardacre, C., \& Migaud, M. E. (2021). Applications of Mechanochemistry for the Synthesis of DNA on Ionic Liquid Supports. Chemistry - Methods, 1(8), 382-388. https://doi.org/10.1002/cmtd.202100002

\author{
Published in: \\ Chemistry - Methods
}

Document Version:

Publisher's PDF, also known as Version of record

Queen's University Belfast - Research Portal:

Link to publication record in Queen's University Belfast Research Portal

\section{Publisher rights}

Copyright 2021 the authors.

This is an open access Creative Commons Attribution-NonCommercial License (https://creativecommons.org/licenses/by-nc/4.0/), which permits use, distribution and reproduction for non-commercial purposes, provided the author and source are cited.

\section{General rights}

Copyright for the publications made accessible via the Queen's University Belfast Research Portal is retained by the author(s) and / or other copyright owners and it is a condition of accessing these publications that users recognise and abide by the legal requirements associated with these rights.

Take down policy

The Research Portal is Queen's institutional repository that provides access to Queen's research output. Every effort has been made to ensure that content in the Research Portal does not infringe any person's rights, or applicable UK laws. If you discover content in the Research Portal that you believe breaches copyright or violates any law, please contact openaccess@qub.ac.uk. 


\title{
Applications of Mechanochemistry for the Synthesis of DNA on Ionic Liquid Supports
}

\author{
Christopher Johnston, ${ }^{[b]}$ Christopher Hardacre, ${ }^{[c]}$ and Marie E. Migaud ${ }^{*[a, b]}$
}

The standard methodology for the synthesis of oligonucleotides is the solid-phase method. Here, we report the first case of mechanochemistry being directly applied to synthesising a dinucleotide on a soluble support. While mechanochemistry eliminates the need to solubilise a supported oligomer in the solution phase for phosphoramidite coupling, the support still confers the benefit of being able to purify the product by precipitation or by simple liquid-liquid extractions as needed. Furthermore, this study also explores the use of mechanochemistry in the initial functionalisation of the ionic liquid support with a nucleoside monomer.

\section{Introduction}

Following the successful demonstration of oligonucleotide synthesis in conjunction with polymeric supports, ${ }^{[1-3]}$ solidphase methodologies have become the standard means for industrial production of these compounds. This approach, in which the synthesis of a growing oligomer chain is carried out on an insoluble support, allows the removal of excess reagents and by-products after each reaction step by simple washing of the solid phase. However, several problems remain with this approach. These include the need for large excesses of reagents to achieve satisfactory coupling efficiencies, the use of expensive non-reusable polymeric supports, and finally, the use of large volumes of solvents ${ }^{[4,5]}$ for solubilisation of the nonimmobilised reagents and washing the solid support following reactions.

To reduce costs and waste, tractable supports that are soluble in the solvent/reagent phase to maximise mass transfer

[a] Prof. M. E. Migaud

Department of Pharmacology

Mitchell Cancer Institute

1660 Spring Hill Avenue

Mobile, Alabama (USA)

E-mail: mmigaud@southalabama.edu

[b] Dr. C. Johnston, Prof. M. E. Migaud

School of Pharmacy

Queen's University Belfast

97 Lisburn Road

Belfast (UK)

[c] Prof. C. Hardacre

The Mill

Sackville Street Campus

The University of Manchester

Manchester (UK)

Supporting information for this article is available on the WWW under https://doi.org/10.1002/cmtd.202100002

This publication is part of a joint Special Collection of Chemistry-Methods and ChemSusChem including invited contributions focusing on "Methods and Applications in Mechanochemistry.

C (c) 2021 The Authors. Published by Wiley-VCH GmbH. This is an open access article under the terms of the Creative Commons Attribution Non-Commercial License, which permits use, distribution and reproduction in any medium, provided the original work is properly cited and is not used for commercial purposes. have been explored for the synthesis of oligonucleotides. These restore the benefits of solution-based methods while retaining some of the advantages of solid-phase synthesis. The key feature of such soluble supports is their ability to be separated from the reaction solvent phase either by simple precipitation or by phase separation methods. These properties allow effective purification protocols similar to those applied in solidphase strategies and avoid laborious chromatographic purifications that require large volumes of solvents and resources. The advances which have been made in soluble supports have been covered in a comprehensive review by Lönnberg. ${ }^{[6]}$ The first report of a soluble support appears to be from the late 1980s, when Bonora described the use of soluble polyethylene glycol (PEG) support for oligonucleotide synthesis, ${ }^{[7]}$ later naming the methodology high efficiency liquid phase (HELP) synthesis. ${ }^{[8,9]}$ Other soluble supports that have been studied include a radially symmetric tetrapodal support, ${ }^{[10-14]} \quad \beta$-Cyclodextrins, ${ }^{[15]}$ adamantane, ${ }^{[16]}$ and alkyl chain-based supports. ${ }^{[17]}$ Although PEG is low cost and readily available, the buffering effect of oxygen atoms means that multiple acid treatments may be required to achieve complete detritylation. ${ }^{[18]}$ The hydrophobicity of supports such as $\beta$-cyclodextrins and alkyl chain-based supports is important because it facilitates precipitation from polar solvents or greatly simplifies chromatographic purifications. Adamantane was demonstrated to allow the purification of an oligomer using only liquid-liquid extractions, although precise combinations of organic solvents were required to achieve this. The symmetrical nature of the tetrapodal tetrakisO-(4-azidomethylphenyl)pentaerythritol support is beneficial as it simplifies spectrometric characterisation.

In addition to these, the use of ionic liquids as soluble supports has attracted attention. Since their inception, ionic liquids have been considered green materials and described as "designer solvents." ${ }^{[19-22]}$ This property stems from the wide selection of cations and anions available for the customisable chemical and solubility properties of these chemical entities. The general use of ionic liquids as soluble supports has been reviewed. ${ }^{[23,24]}$ In that context, ionic liquids have been successfully used for the synthesis of oligopeptides ${ }^{[25]}$ and oligosaccharides, ${ }^{[26]}$ although some concern was expressed as to 
whether the technique could be applied to long and complex oligomers due to the changing solubility properties as the oligomer grows. Such ionic liquid-based oligomerisation methodologies were later adapted for oligonucleotide synthesis by the Damha group, who used $\mathrm{N}$-methylimidazolium tetrafluoroborate ionic liquids to synthesise both oligodeoxyribonucleotides ${ }^{[27,28]}$ and oligoribonucleotides. ${ }^{[29]}$ Use of this ionic liquid support was advantageous in allowing purification of the supported oligomer by precipitation from EtOAc and diethyl ether, after quenching excess nucleoside phosphoramidites with ethanol or tert-butanol.

Although the renaissance of solution-phase methods is partly driven by a desire to avoid using large excesses of reagents that are then removed from the solid supports with copious volumes of organic solvents, solution-phase chemistry also requires the use of bulk solvents. Thus, even though an improvement in mass transfer with soluble supports allows for a reduction of reagents used for oligonucleotide synthesis, the amount of solvent waste that is generated over repeated cycles of detritylation, coupling, oxidation, and capping is yet substantial. Consequently, there is a continuing need to develop new synthetic protocols for oligonucleotides, which are more efficient and less wasteful. Mechanochemistry, which involves the induction of chemical reactions by mechanical forces as generated by shaker mills or planetary mills, is regarded as a green method of chemical synthesis. ${ }^{[30]}$ Mechanochemical processes may be performed in the absence of solvent or with the addition of small quantities of solvent to facilitate the reaction by liquid-assisted grinding. ${ }^{[31]}$ Do and Friščic have coined the term "Chemistry 2.0" in reference to the paradigm shift which mechanochemical methodologies may achieve within the near future. ${ }^{[32]}$

This study reports the first case of mechanochemistry being directly applied to the synthesis of a dinucleotide on a soluble support. While mechanochemistry eliminates the need to solubilise a supported oligomer in the solution phase for phosphoramidite coupling, the support still confers the benefit of being able to purify the product by precipitation, or by simple liquid-liquid extractions as needed. Furthermore, this study also explores the use of mechanochemistry in the initial functionalisation of the ionic liquid support with a nucleoside monomer.

\section{Results and Discussion}

The ionic liquid selected for this study was an imidazoliumbased ionic liquid incorporating a bistriflimide anion, 1-(2hydroxyethyl)-3-methylimidazolium bis\{(trifluoromethyl) sulfonyl\}imide $\left(\left[\mathrm{C}_{2} \mathrm{OHmim}\right]\left[\mathrm{NTf}_{2}\right]\right)$. The main consideration for the selection of the ionic liquid was its solubility profile, with the intended function that the resulting dinucleotide could be purified by simple precipitation after phosphoramidite coupling. The bistriflimide anion $\left(\left[\mathrm{NTf}_{2}\right]^{-}\right)$was selected as it confers insolubility in ethereal solvents to the ionic liquids that incorporate it. This property would allow for the separation of ionic species incorporating $\left[\mathrm{NTf}_{2}\right]^{-}$from excess nucleoside phosphoramidites by simple precipitation following addition of diethyl ether or tert-butyl methyl ether (TBME). Although hydrophilic anions such as tetrafluoroborate $\left(\left[\mathrm{BF}_{4}\right]^{-}\right)$have previously been utilised for oligonucleotide synthesis, ${ }^{[27-29]}$ these $\left[\mathrm{BF}_{4}\right]^{-}$-based ionic liquids are undesirable for large scale synthesis, as they are hydrophilic and may accumulate unacceptable water contents. Such ionic liquids have been shown to react with phosphorous-derived reagents, ${ }^{[33]}$ and when combined to water may contribute to the degradation of the valuable phosphoramidite reagents used in oligomerisation of nucleotides. Furthermore, this anion is unstable and may degrade, emitting toxic HF gas. ${ }^{[34]}$ In terms of cations, a range of ammonium cations could be considered for the generation of triflimide-derived ionic partners. In this context, the imidazolium cations have proved to be useful counter ions for the formation of diionic species used in the synthesis of oligomers. ${ }^{[27-29]}$

Thus, we envisioned that a $\left[\mathrm{C}_{2} \mathrm{mim}\right]\left[\mathrm{NTf}_{2}\right]$-derived nucleoside would allow for an efficient dimer formation by phosphoramidite-based coupling, followed by oxidation and purification of the bound-dinucleotide by precipitation using either diethyl ether or TBME. The key to this approach is the hydrophobicity of the conjugated material imparted by the $\left[\mathrm{NTf}_{2}\right]^{-}$anion. This property also facilitates further purification of the dinucleotide using aqueous washes. Critically, the ionic liquid 1-hexyl-3methylimidazolium tris(pentafluoroethyl) trifluorophosphate ([ $\left.\left.\mathrm{C}_{6} \mathrm{mim}\right][\mathrm{FAP}]\right)$ has proven to provide an excellent environment for the storing of reactive nucleoside phosphoramidites and is particularly useful in mechanochemical processes seeking to generate oligonucleotides via these phosphoramidites. ${ }^{[35,36]}$ The conditions investigated here are particularly amenable to $[\mathrm{FAP}]^{-}$-stabilised phosphoramidites, since this $[\mathrm{FAP}]^{-}$-based ionic liquid would then be removed during the precipitation step as $\left[\mathrm{C}_{6} \mathrm{mim}\right][\mathrm{FAP}]$ is soluble in diethyl ether and TBME.

Therefore, the first step was to functionalise the triflimide ionic liquid with a nucleoside, 5'-O-dimethoxytrityl-2'-deoxythymidine (DMT-dT). In oligonucleotide synthesis, the first nucleoside is attached to the support via a dicarboxylic acid, such as a $3^{\prime}$-O-succinyl linking group. ${ }^{[8,9,17,27-29]}$ This is generally achieved by coupling the acid at the 3 '-end of the nucleoside via an ester linkage. This synthesis often uses pyridine, ${ }^{[37]}$ a toxic solvent, along with 4-dimethylaminopyridine (DMAP) as the activator. For comparison, this step was initially performed using conventional solution-phase chemistry (Supporting Information). The nucleoside 1 was functionalised with a 3'-O-succinyl linking group, then coupled with the ionic liquid $\left[\mathrm{C}_{2} \mathrm{OHmim}\right]\left[\mathrm{NTf}_{2}\right]$. Successful formation of the conjugate 3 was confirmed by ${ }^{1} \mathrm{H}$ NMR, as a shift was observed in the $\mathrm{CH}_{2}$ groups of $\left[\mathrm{C}_{2} \mathrm{OHmim}\right]\left[\mathrm{NTf}_{2}\right]$ following ester bond formation (Figure $\mathrm{S} 1$ in the Supporting Information). $\mathrm{N}$-(3-dimethylaminopropyl)- $N$ '-ethylcarbodiimide hydrochloride (EDC. $\mathrm{HCl}$ ) was selected as a coupling reagent as it is water-soluble, facilitating removal of excess reagent and its by-product by simple aqueous washes. An excess of ionic liquid was used to ensure complete consumption of the nucleoside. The excess ionic liquid was removed during the aqueous workup, as although the $\left[\mathrm{NTf}_{2}\right]^{-}$ anion is considered to confer hydrophobicity to the materials they generate, the presence of a hydrophilic hydroxyl group 
promoted solubility of $\left[\mathrm{C}_{2} \mathrm{OHmim}\right]\left[\mathrm{NTf}_{2}\right]$ in aqueous media. For matching cations, $[\mathrm{FAP}]^{-}$-derived ionic liquids display greater hydrophobicity profiles. The same reaction was, therefore, performed using $\left[\mathrm{C}_{2} \mathrm{OHmim}\right][\mathrm{FAP}]$, with increased isolated yields and the resultant molecule characterised (Supporting Information).

Mechanochemistry was then explored as an alternative for this initial coupling of DMT-dT to the ionic liquid support (Scheme 1). Application of the methodology to different aspects of the process is important for establishing effective and green methods of oligomer synthesis that consume less solvents. The E-factor for conventional oligonucleotide synthetic processes on solid supports has been quoted as $4700 \mathrm{Kg} / \mathrm{Kg}^{[5]}$ so there is a need to reduce or eliminate the use of organic solvents from all aspects of the process. Mechanochemical coupling between succinic anhydride and DMT-dT in the presence of DMAP was studied first (Table 1). The reaction did not occur in solventless conditions, so a small volume of dichloromethane (DCM) was incorporated into the reaction vessel to facilitate the reaction by liquid-assisted grinding. The use of 6 equivalents of DCM equated to $70 \mu \mathrm{L}$ for $100 \mathrm{mg}$ of DMT-dT. Upon completion of the reaction, the mixture was taken up in $\mathrm{CDCl}_{3}$ and examined by ${ }^{1} \mathrm{H}$ NMR. Comparison of the peak intensity of the 3 ' proton in the starting material 1 and the product 2 allowed \% conversion

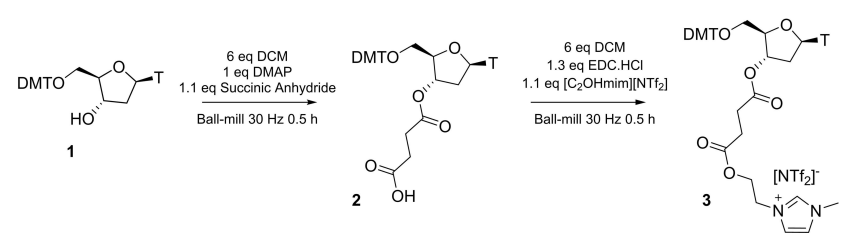

Scheme 1. One-pot mechanochemical preparation of a nucleoside on an ionic liquid support.

\begin{tabular}{|c|c|c|c|c|c|}
\hline Entry & $\begin{array}{l}\text { Succinic } \\
\text { anhydride equiv }\end{array}$ & $\begin{array}{l}\text { DCM } \\
\text { equiv }\end{array}$ & $\begin{array}{l}\text { DMAP } \\
\text { equiv }\end{array}$ & $\begin{array}{l}\text { Reaction } \\
\text { Time [h] }\end{array}$ & $\begin{array}{l}\text { Conversion } \\
{[\%]^{[a]}}\end{array}$ \\
\hline 1 & 1.5 & 1.5 & 1 & 0.5 & 100 \\
\hline 2 & 1.5 & 1 & 1 & 0.5 & 80 \\
\hline 3 & 1.5 & 0.5 & 1 & 0.5 & 64 \\
\hline 4 & 1.1 & 6 & 1 & 0.5 & 100 \\
\hline 5 & 1.1 & 1.5 & 1 & 0.5 & 65 \\
\hline \multirow[t]{3}{*}{6} & 1 & 9 & 1 & 0.5 & 85 \\
\hline & & & & 1 & 86 \\
\hline & & & & 2 & 87 \\
\hline \multirow[t]{2}{*}{7} & 1 & 6 & 1 & 0.5 & 89 \\
\hline & & & & 1 & 91 \\
\hline \multirow[t]{3}{*}{8} & 1 & 3 & 1 & 0.5 & 79 \\
\hline & & & & 1 & 89 \\
\hline & & & & 2 & 89 \\
\hline \multirow[t]{3}{*}{9} & 1.1 & 6 & 0.5 & 0.5 & 92 \\
\hline & & & & 1 & 97 \\
\hline & & & & 2 & 100 \\
\hline \multirow[t]{2}{*}{10} & 1.1 & 6 & 0.1 & 0.5 & 24 \\
\hline & & & & 1 & 35 \\
\hline
\end{tabular}

[a] Determined by integration of corresponding signals in the ${ }^{1} \mathrm{H}$ NMR spectra. of the starting material to the product to be determined quantitatively (Figure S4 in the Supporting Information).

While the addition of 1.5 equivalents of DCM allowed the reaction to go to completion with 1.5 equivalents of succinic anhydride (Table 1, entry 1 ), it was observed that increasing equivalents of DCM allowed a reduction in succinic anhydride (Table 1, entry 4). Minimising the quantity of succinic anhydride was important as this reagent can potentially interfere with subsequent reaction steps. Thus, for optimisation of this procedure, the volume of DCM was selected to allow the use of a minimum mass of succinic anhydride. With the use of 1.5 equivalents, rather than 1.1 equivalents, of succinic anhydride, the increased mass of succinic anhydride allowed the reaction to go to completion, even in the presence of minimal quantities of solvent. Following a reduction in succinic anhydride, the quantity of solvent had to be increased to ensure more intimate mixing between the reactants. However, the ratio of succinic anhydride could not be reduced below 1.1 equivalents; with 1 equivalent of succinic anhydride, incomplete consumption of nucleoside was always observed (Table 1 , entries $6,7,8$ ), which may be due to the presence of water within the milling vessel. The selected optimised conditions were therefore for 1.1 equivalents of succinic anhydride (Table 1, entry 4).

When comparing entries 6,7 , and 8 (Table 1), it was noted that slightly improved outcomes were achieved (by ${ }^{1} \mathrm{H} N M R$ ) in the case of entry 7 , which utilised 6 equivalents of DCM, than entries 6 and 8 , which used 9 and 3 equivalents of DCM, respectively. The idea of an optimal volume of solvent is consistent with a mechanism for solvent-assisted reactions proposed by Bowmaker et al. ${ }^{[38]}$ In the solvent-assisted mechanism, diffusion is the most important process by which reactants move throughout the medium. It is therefore important to ensure that the volume of solvent included is sufficient to provide a medium for diffusion, but also not so excessive so as to increase the diffusion pathlength. Here, the reaction was facilitated by the minimal volumes of liquid that provided a solvent phase for one or more reactants. Thus, while DCM assists the mechanochemical reaction by providing a medium for diffusion, the addition of too much solvent increases the diffusion pathlength and therefore impedes the reaction. This explains why an inferior conversion was achieved with 9 equivalents of DCM (entry 6) compared to 6 equivalents of DCM (entry 7). It is, therefore, important to optimise mechanochemical reactions to use the minimum volume of solvent necessary to achieve complete conversions.

The succinylation of nucleosides has previously been optimised in solution, ${ }^{[39]}$ with the reaction having been found to proceed very rapidly $(10 \mathrm{~min})$ in the presence of a catalytic amount of DMAP ( 0.5 equiv) and succinic anhydride ( 1.5 equiv) at $50^{\circ} \mathrm{C}$ in 1,2-dichloroethane (DCE). Although the optimised milling procedure presented, herein, required $30 \mathrm{~min}$ of milling with 1 equivalent of DMAP, this was achieved using 1.1 equivalents of succinic anhydride rather than 1.5 equivalents, which is the ratio that has previously been selected for optimised procedures. ${ }^{[37,39]}$ Avoiding an excess of succinic anhydride allowed for easier purification, and also opened up the possibility of a one-pot reaction with the next synthetic 
step. The optimised procedure by Kumar et al. utilised only $1 \mathrm{~mL}$ of DCE for the succinylation of $0.5 \mathrm{mmol}$ of nucleoside. ${ }^{[39]}$ Despite this being a relatively small volume of solvent, this equates to over 25 equivalents of solvent relative to the nucleoside. Such volumes of solvent are needed for solutionbased chemistry to ensure dissolution and effective stirring of the reactants. In contrast, the optimised procedure presented here was performed using only 6 equivalents of DCM (Scheme 1), which presents a large decrease in the volume of halogenated solvent used for this reaction. In addition to the reduced volume of solvent used, DCM is also a less toxic choice than DCE. An alternative optimised procedure in the literature, ${ }^{[37]}$ using DCM as the solvent, utilised $100 \mathrm{~mL}$ of solvent for performing the reaction with $10 \mathrm{mmol}$ of nucleoside. In this case, this is over 156 equivalents of solvent relative to the nucleoside. Again, the use of 6 equivalents of solvent compares favourably to this, demonstrating how mechanochemical procedures can be used to perform reactions using solvent volumes which are orders of magnitude less than those used for solutions.

Following the development of mechanochemical conditions for functionalising a nucleoside with a 3 '-O-succinyl linker, this approach was used in a one-pot reaction for subsequently coupling this molecule with an ionic liquid, forming the compound $\mathbf{3}$ on which oligonucleotide synthesis can take place (Scheme 1). Ionic liquids are ideal for use in mechanochemistry as the presence of a liquid phase facilitates mixing and mass transfer in the vessel. The previously optimised procedure (Table 1, entry 4) was used to form the succinylated nucleoside 2. This was then followed by addition of 1.1 equivalents of ionic liquid, 1.3 equivalents of EDC. $\mathrm{HCl}$, and an additional 6 equivalents of DCM, allowing formation of the product 3 in a one-pot procedure after ball-milling for an additional $30 \mathrm{~min}$. Workup of the product was achieved by dissolving the contents of the ball-milling vessel in EtOAc and performing an aqueous extraction with a saturated $\mathrm{NH}_{4} \mathrm{Cl}$ solution. This demonstrates the benefits of mechanochemistry in minimising the volumes of toxic solvents used, with workup being performed using only aqueous washes with EtOAc, a less toxic solvent choice.

The triflimide-based conjugate $\mathbf{3}$ was used to demonstrate mechanochemical coupling with a nucleoside phosphoramidite (Scheme 2), and subsequent purification by precipitation in ether solvents. Detritylation of the ionic liquid-bound nucleoside 3 was performed using $3 \% \mathrm{v} / \mathrm{v}$ trifluoroacetic acid (TFA) in DCM. A trityl scavenger, triethylsilane, was also added to

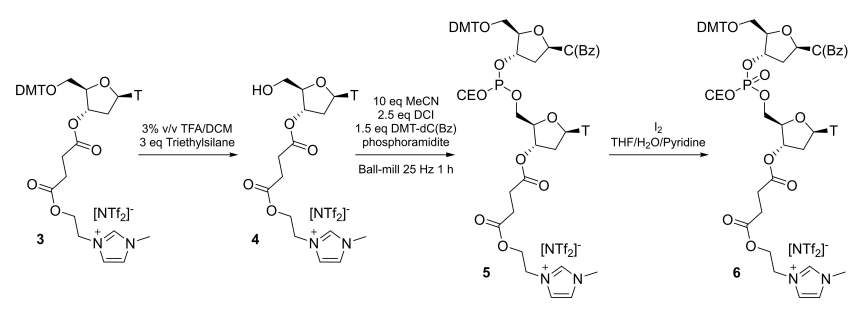

Scheme 2. Deprotection, coupling, and oxidation of a nucleoside on an ionic liquid support. The coupling step was performed under mechanochemical conditions. $\mathrm{CEO}=\mathrm{CNCH}_{2} \mathrm{CH}_{2} \mathrm{O}$. prevent retritylation of the molecule following addition of the solution to the precipitation medium and a consequent dilution of the acid, which would shift the equilibrium in favour of the reverse reaction. This scavenger has previously been used for deprotection of ionic liquid-bound nucleosides. ${ }^{[40]}$ After observing decolouration of the reaction medium, the solution was added dropwise to stirring TBME to precipitate the product, while the by-products remained dissolved. DCM can promote solubilisation of the deprotected ionic liquid-bound nucleoside 4 during the precipitation step, but as the boiling point of TBME is higher than DCM, it was possible to selectively remove DCM under reduced pressure, preventing redissolution of 4 . The deprotection step was performed two additional times, ensuring complete removal of the dimethoxytrityl (DMT) protecting group. ${ }^{1} \mathrm{H}$ NMR confirmed complete removal of the DMT protecting group and the absence of aromatic peaks (Figure S7 in the Supporting Information). However, ${ }^{19} \mathrm{~F}$ NMR indicated the presence of the [TFA] ${ }^{-}$anion in addition to the $\left[\mathrm{NTf}_{2}\right]^{-}$anion (Figure S8 in the Supporting Information). ${ }^{1} \mathrm{H}$ NMR also confirmed that depyrimidation did not occur during the DMT cleavage.

A mechanochemical coupling step was then performed between a nucleoside phosphoramidite, $N^{4}$-Benzoyl-5'-O-(4,4'dimethoxytrityl)-2'-deoxycytidine-3'-O-[O-(2-cyanoethyl)- $N, N^{\prime}-$ diisopropyl phosphoramidite (DMT-dC(Bz) phosphoramidite), and the deprotected ionic liquid-bound nucleoside 4. Couplings of monomers by the phosphoramidite method under mechanochemical conditions have previously been reported by Thorpe et al., ${ }^{[4]}$ but this is the first case of mechanochemistry being applied to a support designed to facilitate purification of a growing oligomer by precipitation, or liquid-liquid extraction. The deprotected ionic liquid-bound nucleoside $\mathbf{4}$ was dissolved in a minimal volume of acetone and added to a ball-milling vessel. Following evaporation of the acetone, the milling vessel was placed under high vacuum at $70^{\circ} \mathrm{C}$ overnight to facilitate removal of any residual acetone and water. ${ }^{1} \mathrm{H}$ NMR confirmed that depyrimidation again did not occur after $\mathbf{4}$ was subjected to these conditions (Figure 59 in the Supporting Information). The first reaction attempted was milling of 4 with $\mathrm{DMT}-\mathrm{dC}(\mathrm{Bz})$ phosphoramidite and an activator, 4,5-dicyanoimidazole (DCl), at $25 \mathrm{~Hz}$ for $1 \mathrm{~h}$. However, finely milled solid particles were observed following the milling, indicating poor mass transfer and mixing. When analysed by ${ }^{31} \mathrm{P} N M R$, only unreacted DMT$\mathrm{dC}(\mathrm{Bz})$ phosphoramidite and a degradation product, the corresponding $\mathrm{H}$-phosphonate, were detected. A small volume of anhydrous acetonitrile ( $\mathrm{MeCN}$ ) was also examined as an addition to the milling vessel to facilitate the reaction by liquidassisted grinding. ${ }^{[31]} 5$ equivalents of $\mathrm{MeCN}$ was added to the deprotected compound 4 and $\mathrm{DMT}-\mathrm{dC}(\mathrm{Bz})$ phosphoramidite, followed by pre-milling of the reactants for $5 \mathrm{~min}$. A further 5 equivalents of $\mathrm{MeCN}$ was added, along with 2.5 equivalents of $\mathrm{DCl}$, followed by milling for $1 \mathrm{~h}$ (Scheme 2). Upon completion of the reaction, two peaks were observed by ${ }^{31} \mathrm{P}$ NMR at 139.53 and $139.49 \mathrm{ppm}$, confirming the presence of the desired dinucleoside phosphite. The remaining nucleoside phosphoramidite had hydrolysed to form the $H$-phosphonate (Figure S11 in the Supporting Information). 
Formation of the dinucleoside product 5 was lower than expected, with peak integration ratios by ${ }^{31} \mathrm{P}$ NMR $(33 \%$ for the dinucleoside phosphite, $67 \%$ for the $H$-phosphonate degradation product) indicating that 1 equivalent of nucleoside phosphoramidite had hydrolysed, whereas 0.5 equivalents had reacted. With 1.5 equivalents of nucleoside phosphoramidite and 1 equivalent of 4 having been used, this corresponds to a coupling efficiency of $50 \%$. The low coupling efficiency observed could be due to the persistence of residual water in $\mathbf{4}$, which could be removed by co-evaporation. Furthermore, the small scale on which the coupling was performed would likely contribute to an increased ratio of the hydrolysis product, and greater stability could be observed on a larger scale. In addition, the use of $\left[\mathrm{C}_{6} \mathrm{mim}\right][\mathrm{FAP}]$-stabilised nucleoside phosphoramidites incorporating smaller, more-reactive amine functionalities could allow for improved coupling efficiencies, ${ }^{[35]}$ and possibly even one-pot couplings. The $\left[\mathrm{C}_{6} \mathrm{mim}\right][\mathrm{FAP}]$ ionic liquid used to stabilise the nucleoside phosphoramidites would be removed from the growing oligomer upon precipitation of the product in an ethereal solvent. Finally, oxidation of the ionic-liquid bound dinucleoside 5 using a $0.1 \mathrm{moldm}^{-3}$ solution of $\mathrm{I}_{2}$ in pyridine/ water/tetrahydrofuran (THF) was done by dropwise addition of this solution until the iodine colour persisted. Dissolution of the mixture in EtOAc, followed by aqueous washes with sodium thiosulfate solution, saturated $\mathrm{NaHCO}_{3}$ solution, and evaporation of the solvent under reduced pressure afforded the ionic liquid-bound dinucleotide 6 in a yield of $38 \%$ (Figure S12 in the Supporting Information).

The use of ionic liquids also presents the possibility to alter the solubility properties of a growing oligomer by performing anion exchange. This was demonstrated here by adding $\left[\mathrm{C}_{2} \mathrm{OHmim}\right][\mathrm{FAP}]$ to the ionic-liquid bound dinucleotide 6 followed by an aqueous wash (Scheme S1 in the Supporting Information). ${ }^{19} \mathrm{~F}$ NMR analysis showed that the $\left[\mathrm{NTf}_{2}\right]^{-}$anion had been completely removed from the conjugate and replaced by the $[\mathrm{FAP}]^{-}$anion (Figure S14 in the Supporting Information). The solubility and precipitation properties of soluble supports are important, both in terms of determining the nature of the precipitation medium used, and which media are used for liquid-liquid extractions. Koning et al. ${ }^{[16]}$ carefully selected combinations of organic solvents to ensure solubility of the oligomer in the organic phase, while also ensuring the removal of uncoupled $\mathrm{H}$-phosphonate in the aqueous phase. Anion exchange of an ionic liquid-bound oligomer could alter the solubility and precipitation properties of an oligomer midway through its synthesis, without having to cleave the oligomer from the cation functionality of the molecule. This may be useful due to the changing chemical properties of an oligomer as it increases in length and presents a unique advantage of ionic liquids over other supports that cannot be modified as easily.

\section{Conclusion}

In conclusion, there is a significant need to reduce the volumes of solvent used for synthesis, and this is true for the soluble support method of oligonucleotide synthesis, despite the advantages it brings over established solid-phase methods. Herein, the concept of using an ionic liquid support in combination with liquid-assisted mechanochemistry was demonstrated for various aspects of oligonucleotide synthesis. Future work will be needed to expand mechanochemistry to all aspects of oligonucleotide synthesis, and to improve phosphoramidite coupling efficiencies. While the term "soluble support" is commonly used, and has indeed been used here, this work presents a shift away from the idea of a support having to be soluble to facilitate solution-phase chemistry, and instead emphasises the primary role of the support in allowing for purification by precipitation or liquid-liquid extraction. The principle of carrying out the coupling step under mechanochemical conditions will prove to be beneficial when performing the coupling with hydrolytically-sensitive $\left[C_{6}\right.$ mim] $[F A P]-$ stabilised nucleoside phosphoramidites, ${ }^{[35]}$ and this also remains to be investigated. With multiple steps for the synthesis of oligonucleotides having been demonstrated to be mechanochemically feasible (Scheme S2, in the Supporting Information), it is envisaged that oligonucleotide synthesis in the future will consume lower volumes of solvents.

\section{Experimental Section}

\section{Experimental Methods}

All reactions requiring anhydrous or inert conditions were carried out under an atmosphere of argon or nitrogen in oven-dried glassware. Reactions stirred magnetically were performed using Teflon-coated stirring bars. Ball-milled reactions were performed in oven-dried Retsch $1.5 \mathrm{~mL}$ steel vessels, incorporating a single $5 \mathrm{~mm}$ steel ball, on a Retsch Mixer Mill MM400, with masses of reagents being weighed directly into the vessels. Organic solvents were introduced into the steel vessels using oven-dried Hamilton syringes. Organic solutions washed with aqueous solutions were dried using $\mathrm{MgSO}_{4}$. Solvents were evaporated from round bottom flasks using a rotary evaporator or under high vacuum (0.5$1 \mathrm{mmHg}$ ). DCM and MeCN were distilled over $\mathrm{CaH}_{2}$. Toluene and pyridine were dried by storage with activated $4 \AA$ molecular sieves for $24-72 \mathrm{~h}$ under nitrogen. All other solvents and reagents were used as received from commercial suppliers. DCl, EDC. $\mathrm{HCl}$, DMAP, and succinic anhydride were purchased from Sigma-Aldrich Chemical Company. DMT-dT and DMT-dC(Bz) phosphoramidite were purchased from Carbosynth. [ $\left.\mathrm{C}_{2} \mathrm{OHmim}\right]\left[\mathrm{NTf}_{2}\right]$ and $\left[\mathrm{C}_{2} \mathrm{OHmim}\right][\mathrm{FAP}]$ were generously donated by Merck KGaA. Solvents used for extractions and precipitations were of technical grade, while solvents used in reactions were distilled before use. Analytical TLC was performed with Merck silica gel $60 \mathrm{~F}_{254}$ plates. Visualisation of TLC plates was performed by UV $(\lambda=254 \mathrm{~nm})$ and/or by staining the plate with an anisaldehyde or potassium permanganate solution, followed by heating. ${ }^{1} \mathrm{H},{ }^{13} \mathrm{C},{ }^{31} \mathrm{P},{ }^{19} \mathrm{~F}$ and $2 \mathrm{D}(\mathrm{H}$-COSY, HSQC) NMR spectra were recorded on Brüker Advance DPX 400 and Brüker Ascend 600. TMS (0 ppm, ${ }^{1} \mathrm{H}$ NMR), $\mathrm{CDCl}_{3}$ (77 ppm, ${ }^{13} \mathrm{C}$ NMR), $\left(\mathrm{CD}_{3}\right)_{2} \mathrm{CO}$ (2.05 ppm, ' $\mathrm{H}$ NMR, $\left.29.92 \mathrm{ppm},{ }^{13} \mathrm{C} \mathrm{NMR}\right)$ and $\mathrm{CD}_{3} \mathrm{CN}$ (1.94 ppm, ${ }^{1} \mathrm{H}$ NMR, $1.39 \mathrm{ppm},{ }^{13} \mathrm{C}$ NMR) were used as internal references. The chemical shifts are reported in ppm (parts per million). High resolution mass spectrometry (HRMS) was recorded on a VG Quattro Triple Quadropole Mass Spectrometer (ES). 
Mechanochemical Synthesis of

5'-O-DMT-3'-O-succinyl-2'-deoxythymidine (2)

To DMT-dT (100 mg, $0.184 \mathrm{mmol}, 1$ equiv) in a Retsch $1.5 \mathrm{~mL}$ steel vessel, DMAP (22 mg, $0.184 \mathrm{mmol}, 1$ equiv) and succinic anhydride (20 mg, $0.202 \mathrm{mmol}, 1.1$ equiv) were added. DCM (70 $\mu \mathrm{L}$, $1.10 \mathrm{mmol}, 6$ equiv) was then added and the vessel closed immediately. The vessel, containing a $5 \mathrm{~mm}$ diameter steel ball, was shaken using a Retsch MM400 mixer mill at $30 \mathrm{~Hz}$ for $0.5 \mathrm{~h}$. Upon completion of the reaction, the mixture, observed as a paste, was taken up in $\mathrm{CDCl}_{3}$ and analysis by ${ }^{1} \mathrm{H}$ NMR showed quantitative conversion to the product. Dilution of the reaction with $\mathrm{DCM}$, followed by washes with aqueous $\mathrm{NH}_{4} \mathrm{Cl}$, brine, drying with $\mathrm{MgSO}_{4}$, and subsequent evaporation of solvent afforded the product as a white solid in a $74 \%$ yield $(88 \mathrm{mg}, 0.137 \mathrm{mmol}){ }^{1} \mathrm{H}$ NMR $(400 \mathrm{MHz}$, $\left.\mathrm{CDCl}_{3}\right) \mathrm{ppm} 1.36(\mathrm{~s}, 3 \mathrm{H}), 2.34-2.55(\mathrm{~m}, 2 \mathrm{H}), 2.59-2.73(\mathrm{~m}, 4 \mathrm{H}), 3.39$ $3.53(\mathrm{~m}, 2 \mathrm{H}), 3.79(\mathrm{~s}, 6 \mathrm{H}), 4.16-4.20(\mathrm{~m}, 1 \mathrm{H}), 5.43-5.51(\mathrm{~m}, 1 \mathrm{H}), 6.36-$ $6.45(\mathrm{~m}, 1 \mathrm{H}), 6.80-6.88(\mathrm{~m}, 4 \mathrm{H}), 7.20-7.34(\mathrm{~m}, 7 \mathrm{H}$, Aromatic H), 7.34$7.32(\mathrm{~m}, 2 \mathrm{H}$, Aromatic $\mathrm{H}), 7.62(\mathrm{~s}, 1 \mathrm{H}), 9.10$ (broad s, 1H); ${ }^{13} \mathrm{C}$ NMR $\left(100 \mathrm{MHz}, \mathrm{CDCl}_{3}\right)$ ppm 11.6, 29.7, 37.9, 55.2, 63.7, 75.7, 83.5, 84.4, 87.1, 111.8, 113.3 (Aromatic C), 127.2 (Aromatic C), 128.0 (Aromatic C), 128.1 (Aromatic C), 130.0 (Aromatic C), 130.1 (Aromatic C), 135.1 (Aromatic C), 135.2 (Aromatic C), 135.6, 144.2 (Aromatic C), 150.9, 158.8 (Aromatic C), 158.7 (Aromatic C), 164.2, 172.0, 176.5; MS (ES) Calc $643.2292(\mathrm{M}-\mathrm{H})^{-}$, Found 643.2189, Calc $1287.4662(2 \mathrm{M}-\mathrm{H})^{-}$ Found 1287.4688; NMR data in general agreement with previously published work. ${ }^{[39]}$

\section{One-Pot Mechanochemical Synthesis of 5'-O-DMT-2'-deoxy-3'-O-(succ-[ $\mathrm{C}_{2}$ mim] $\left.\left[\mathrm{NTf}_{2}\right]\right)$ thymidine (3)}

To DMT-dT (100 mg, $0.184 \mathrm{mmol}, 1$ equiv) in a Retsch $1.5 \mathrm{~mL}$ steel vessel, DMAP (22 mg, $0.184 \mathrm{mmol}, 1$ equiv) and succinic anhydride (20 mg, $0.202 \mathrm{mmol}, 1.1$ equiv) were added. DCM (70 $\mu \mathrm{L}$, $1.10 \mathrm{mmol}$, 6 equiv) was then added and the vessel closed immediately. The vessel, containing a $5 \mathrm{~mm}$ diameter steel ball, was shaken using a Retsch MM400 mixer mill at $30 \mathrm{~Hz}$ for $0.5 \mathrm{~h}$. Following this, $\left[\mathrm{C}_{2} \mathrm{OHmim}\right]\left[\mathrm{NTf}_{2}\right](82 \mathrm{mg}, 0.202 \mathrm{mmol}, 1.1$ equiv) and EDC. $\mathrm{HCl}$ ( $46 \mathrm{mg}, 0.239 \mathrm{mmol}, 1.3$ equiv) were added to the vessel, along with additional DCM (70 $\mu \mathrm{L}, 1.10 \mathrm{mmol}, 6$ equiv) and milled for a further $0.5 \mathrm{~h}$ at $30 \mathrm{~Hz}$. The vessel was rinsed using EtOAc, and a wash with aqueous $\mathrm{NH}_{4} \mathrm{Cl}$ and brine was performed. The organic layer was dried using $\mathrm{MgSO}_{4}$, followed by evaporation of EtOAC under reduced pressure to afford the product as a white solid in $45 \%$ yield $(86 \mathrm{mg}, 0.083 \mathrm{mmol}){ }^{1} \mathrm{H}$ NMR $\left(400 \mathrm{MHz},\left(\mathrm{CD}_{3}\right)_{2} \mathrm{CO}\right) \mathrm{ppm}$ $1.41(\mathrm{~s}, 3 \mathrm{H}), 2.37-2.65(\mathrm{~m}, 2 \mathrm{H}), 2.67$ (broad s, 4H), 3.37-3.53 (m, 2H), $3.78(\mathrm{~s}, 6 \mathrm{H}), 4.05(\mathrm{~s}, 3 \mathrm{H}), 4.12-4.18(\mathrm{~m}, 1 \mathrm{H}), 4.52-4.57(\mathrm{~m}, 2 \mathrm{H}), 4.66-$ $4.71(\mathrm{~m}, 2 \mathrm{H}), 5.43-5.53(\mathrm{~m}, 1 \mathrm{H}), 6.30-6.39(\mathrm{~m}, 1 \mathrm{H}), 6.84-6.97(\mathrm{~m}, 4 \mathrm{H})$, 7.20-7.39 (m, 7H, Aromatic H), 7.45-7.52 (m, 2H, Aromatic $\mathrm{H}), 7.63$ $(\mathrm{s}, 1 \mathrm{H}), 7.68-7.71(\mathrm{~m}, 1 \mathrm{H}), 7.80-7.84(\mathrm{~m}, 1 \mathrm{H}), 9.10(\mathrm{~s}, 1 \mathrm{H}), 10.14(\mathrm{~s}$, $1 \mathrm{H}) ;{ }^{13} \mathrm{C}$ NMR $\left(100 \mathrm{MHz},\left(\mathrm{CD}_{3}\right)_{2} \mathrm{CO}\right) \mathrm{ppm} 12.1,29.3,36.8,38.0,49.6$, $55.6,63.3,64.8,76.5,84.6,85.1,87.8,111.5,114.1,121.1$ (quartet, $2 \times$ $\mathrm{CF}_{3}, J=321.5 \mathrm{~Hz}$ ), 124.1, 124.9, 127.9 (Aromatic C), 128.8 (Aromatic C), 129.1 (Aromatic C), 131.1 (Aromatic C), 136.3, 136.4 (Aromatic C), 136.5 (Aromatic C), 138.1, 145.8 (Aromatic C), 151.5, 159.8 (Aromatic C), 159.9 (Aromatic C), 164.3, 172.6, 172.6; ${ }^{19} \mathrm{~F}$ NMR $(377 \mathrm{MHz}$, $\left.\left(\mathrm{CD}_{3}\right)_{2} \mathrm{CO}\right) \mathrm{ppm}-79.9$; MS (ES) Calc $753.3136\left(\mathrm{M}^{+}\right)$, Found 753.3120, Calc 279.9173, $\left(\mathrm{M}^{-}\right)$, Found 279.9163; NMR data of the cation in general agreement with previously published work. ${ }^{[27]}$

\section{Synthesis of 5'-OH-2'-deoxy-3'-O-(succ-[ $\mathrm{C}_{2}$ mim] $\left.\left[\mathrm{NTf}_{2}\right]\right)$ thymidine (4)}

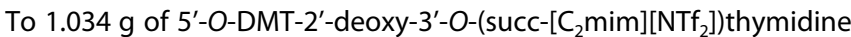
( $1 \mathrm{mmol}, 1$ equiv), $10 \mathrm{~mL}$ of a solution of $3 \% \mathrm{v} / \mathrm{v}$ TFA in DCM was added and stirred for $10 \mathrm{~min}$. Following this, triethylsilane $(0.35 \mathrm{~g}$,
$3 \mathrm{mmol}, 3$ equiv) was added, and the reaction stirred until the colour of the solution changed from orange/red to colourless. The mixture was then added dropwise to $100 \mathrm{~mL}$ of stirred TBME. Selective removal of DCM was achieved using reduced pressure (800 mbar), to prevent redissolution of the desired compound in the DCM/TBME mixture. The precipitated product could be recovered either by decanting solvent from the round-bottom flask and subsequently dissolving the remaining product in acetone, or by centrifugation of the solution to concentrate the precipitate at the bottom of the tube. This procedure was repeated twice to improve purity. The product was obtained as a white semi-solid in a yield of $94 \%(0.69 \mathrm{~g}, 0.94 \mathrm{mmol})$. Remaining DMT peaks following three deprotections were integrated by ${ }^{1} \mathrm{H}$ NMR, and indicated deprotection exceeding $98.5 \%$. ${ }^{1} \mathrm{H}$ NMR $\left(400 \mathrm{MHz},\left(\mathrm{CD}_{3}\right)_{2} \mathrm{CO}\right) \mathrm{ppm}$ $1.82(\mathrm{~s}, 3 \mathrm{H}), 2.25-2.48(\mathrm{~m}, 2 \mathrm{H}), 2.67(\mathrm{~s}, 4 \mathrm{H}), 3.78-3.89(\mathrm{~m}, 2 \mathrm{H}), 4.05(\mathrm{~s}$, $3 \mathrm{H}), 4.03-4.10(\mathrm{~m}, 1 \mathrm{H}), 4.51-4.58(\mathrm{~m}, 2 \mathrm{H}), 4.62-4.70(\mathrm{~m}, 2 \mathrm{H}), 5.31-$ $5.41(\mathrm{~m}, 1 \mathrm{H}), 6.21-6.33(\mathrm{~m}, 1 \mathrm{H}), 7.69(\mathrm{~s}, 1 \mathrm{H}), 7.78(\mathrm{~s}, 1 \mathrm{H}), 7.85(\mathrm{~s}, 1 \mathrm{H})$, $9.05(\mathrm{~s}, 1 \mathrm{H}), 10.34$ (broad s, $1 \mathrm{H}) ;{ }^{13} \mathrm{C}$ NMR $\left(100 \mathrm{MHz},\left(\mathrm{CD}_{3}\right)_{2} \mathrm{CO}\right) \mathrm{ppm}$ $12.6,29.6,36.7,37.8,49.5,62.9,63.2,76.4,85.6,85.9,111.2,120.9$ (quartet, $2 \times \mathrm{CF}_{3}, J=321.5 \mathrm{~Hz}$ ), 123.9, 124.8, 137.2, 138.0, 151.7, 164.7, 172.6, $172.7 ;{ }^{19} \mathrm{~F}$ NMR $\left(377 \mathrm{MHz},\left(\mathrm{CD}_{3}\right)_{2} \mathrm{CO}\right) \mathrm{ppm}-79.8$; MS (ES) Calc 451.1829 $\left(\mathrm{M}^{+}\right)$, Found 451.1817, Calc $279.9173\left(\mathrm{M}^{-}\right)$, Found 279.9165; NMR data of the cation in general agreement with previously published work. ${ }^{[27]}$

\section{Mechanochemical Synthesis of 5'-O-DMT-dC(Bz)-3'-5'-dT-3'-Succ- $\left[\mathrm{C}_{2}\right.$ mim] $\left[\mathrm{NTf}_{2}\right]$ (6)}

5'-OH-2'-deoxy-3'-O-(succinyl-[ $\mathrm{C}_{2}$ mim] $\left[\mathrm{NTf}_{2}\right]$ )thymidine (39.7 mg, $0.054 \mathrm{mmol}, 1$ equiv) was taken up in acetone and added to a Retsch $1.5 \mathrm{~mL}$ steel vessel. Acetone inside the milling vessel was allowed to evaporate inside a fumehood over $1 \mathrm{~h}$, until further evaporation and drying by high vacuum was possible. The vessel was then placed under high vacuum at $70^{\circ} \mathrm{C}$ overnight to dry the material inside the vessel and remove any traces of acetone. The vacuum was broken using $\mathrm{N}_{2}$, and $\mathrm{DMT}-\mathrm{dC}(\mathrm{Bz})$ phosphoramidite ( $68 \mathrm{mg}, 0.081 \mathrm{mmol}, 1.5$ equiv), which had previously been coevaporated three times using toluene, was added to the vessel. The reactants were pre-milled for $5 \mathrm{~min}$ at $25 \mathrm{~Hz}$ in anhydrous MeCN $(11 \mu \mathrm{L}, 0.27 \mathrm{mmol}, 5$ equiv), followed by addition of $\mathrm{DCl}(16 \mathrm{mg}$, $0.136 \mathrm{mmol}, 2.5$ equiv) and additional $\mathrm{MeCN}(11 \mu \mathrm{L}, 0.27 \mathrm{mmol}$, 5 equiv) and further ball-milling for $1 \mathrm{~h}$ at $25 \mathrm{~Hz}$. Upon completion of the reaction, the mixture was taken up in $\mathrm{CDCl}_{3}$, and conversion to the desired $\mathrm{PO}_{3}$ product determined by examination of the relative integration ratios of the $\mathrm{PO}_{3}$ peaks and the $\mathrm{H}$-phosphate peak as observed by ${ }^{31} \mathrm{P}$ NMR. The mixture was diluted with a small volume of $\mathrm{MeCN}$, and oxidised using a mixture of $\mathrm{I}_{2}\left(0.1 \mathrm{~mol} \mathrm{dm}^{-3}\right)$ in pyridine $/ \mathrm{H}_{2} \mathrm{O} / \mathrm{THF}(1: 2: 10 \mathrm{v} / \mathrm{v} / \mathrm{v})$ until the iodine colour persisted. The mixture was concentrated under reduced pressure and taken up in EtOAc. The organic phase was washed using aqueous sodium thiosulfate $5 \% \mathrm{~W} / \mathrm{v}$ (removal of $\mathrm{I}_{2}$ and $\mathrm{I}^{-}$) and aqueous $\mathrm{NaHCO}_{3} 10 \%$ $\mathrm{w} / \mathrm{v}$ (removal of $\mathrm{DCl})$. Unreacted starting material and undesired phosphodiester, formed by oxidation of the $\mathrm{H}$-phosphonate byproduct, were both removed in the aqueous washes. The compound was purified further by dissolution in a minimal volume of DCM and precipitation by dropwise addition to stirring TBME, with the precipitate being collected by centrifugation. Trace solvents were removed from the precipitate under high vacuum, forming the product as a white solid in a yield of $38 \%$ (31 mg, $0.021 \mathrm{mmol}$ ) which was subsequently characterised by NMR and MS. ${ }^{1} \mathrm{H}$ and ${ }^{13} \mathrm{C}$ spectra were complicated due to the formation of a diastereoisomeric mixture. ${ }^{1} \mathrm{H}$ NMR $\left(600 \mathrm{MHz}, \mathrm{CD}_{3} \mathrm{CN}\right)$ ppm 1.80 (broad s, $6 \mathrm{H}$ ), 2.26-2.32 (m, 4H), 2.37-2.45 (m, 2H), $2.60(\mathrm{~s}, 4 \mathrm{H}), 2.61(\mathrm{~s}, 4 \mathrm{H}), 2.75(\mathrm{t}$, $2 \mathrm{H}, J=6.0 \mathrm{~Hz}), 2.76(\mathrm{t}, 2 \mathrm{H}, J=6.5 \mathrm{~Hz}), 2.76-2.83(\mathrm{~m}, 2 \mathrm{H}), 3.34-3.44$ $(\mathrm{m}, 4 \mathrm{H}), 3.75-3.77(\mathrm{~m}, 12 \mathrm{H}), 3.83$ (broad $\mathrm{s}, 6 \mathrm{H}), 4.12-4.23(\mathrm{~m}, 6 \mathrm{H})$, $4.23-4.30(\mathrm{~m}, 4 \mathrm{H}), 4.31-4.40(\mathrm{~m}, 2 \mathrm{H}), 4.37(\mathrm{~s}, 4 \mathrm{H}), 4.38(\mathrm{~s}, 4 \mathrm{H}), 5.04-$ 
$5.12(\mathrm{~m}, 2 \mathrm{H}), 5.19-5.26(\mathrm{~m}, 2 \mathrm{H}), 6.08-6.18(\mathrm{~m}, 4 \mathrm{H}), 6.86-6.90(\mathrm{~m}, 8 \mathrm{H})$ 7.22-7.44 (m, 26H (DMT $\times 18)), 7.49-7.54(m, 4 \mathrm{H}$, Benzoyl), 7.60-7.65 ( $\mathrm{m}, 2 \mathrm{H}$, Benzoyl), $7.96(\mathrm{t}, 4 \mathrm{H}, J=7.5 \mathrm{~Hz}$, Benzoyl), 8.08-8.14 $(\mathrm{m}, 2 \mathrm{H})$, $8.50(\mathrm{~s}, 1 \mathrm{H}), 8.52(\mathrm{~s}, 1 \mathrm{H}), 9.13$ (broad s, 2H), 9.28 (broad s, $2 \mathrm{H}) ;{ }^{13} \mathrm{C}$ NMR $\left(151 \mathrm{MHz}, \mathrm{CD}_{3} \mathrm{CN}\right)$ ppm 12.7 and 12.7, 20.4, 20.4, 29.5, 29.5, 29.7, 29.8, 37.1, 37.2, 37.3, 40.5, 49.6, 56.0, 56.0, 63.2, 63.4, 63.5, 63.8-64.1, 68.5-68.7, 75.1, 75.1, 78.8-79.2, 83.1, 83.2, 85.7-85.9, $86.0-86.1,87.9-88.0,88.0,88.1,111.9,114.3,121.0$ (quartet, $4 \times \mathrm{CF}_{3}$ $J=320.5 \mathrm{~Hz}$ ), 123.9, 124.8, 128.1 (DMT), 128.7-129.1 (DMT), 129.1 (Benzoyl), 129.7 (Benzoyl), 130.1 (DMT), 131.1 (DMT), 131.1 (DMT), 131.2 (DMT), 134.0 (Benzoyl), 136.3-136.6 (DMT), 136.7, 137.6, 137.7, 145.6 (DMT), 145.6, 151.5, 159.9, 159.9, 164.5, 172.9, 172.9, 173.0, 173.0; ${ }^{19} \mathrm{~F}$ NMR $\left(565 \mathrm{MHz}, \mathrm{CD}_{3} \mathrm{CN}\right) \mathrm{ppm}-80.2 ;{ }^{31} \mathrm{P}$ NMR $(243 \mathrm{MHz}$ $\left.\mathrm{CD}_{3} \mathrm{CN}\right)$ ppm -1.26, -1.07; MS (ES) Calc $1199.4127\left(\mathrm{M}^{+}\right)$, Found 1199.3870, Calc 279.9173 $\left(\mathrm{M}^{-}\right)$, Found 279.8506.

\section{Anion Exchange to form 5'-O-DMT-dC(Bz)-3'-5'-dT-3'-Succ-[C ${ }_{2}$ mim] [FAP]}

5'-O-DMT-dC(Bz)-3'-5'-dT-3'-Succ-[C ${ }_{2}$ mim] $\left[\mathrm{NTf}_{2}\right](31 \mathrm{mg}, 0.021 \mathrm{mmol}$, 1 equiv) was dissolved in DCM with $\left[\mathrm{C}_{2} \mathrm{OHmim}\right][\mathrm{FAP}](12 \mathrm{mg}$, $0.023 \mathrm{mmol}$, 1.1 equiv) and washed with water, forming the product as an off-white solid following removal of the solvent. Analysis by ${ }^{19} \mathrm{~F}$ NMR indicated the absence of the $\left[\mathrm{NTf}_{2}\right]^{-}$anion, while ${ }^{1} \mathrm{H}$ NMR and ${ }^{31} \mathrm{P}$ NMR confirmed the presence of the cation. ${ }^{1} \mathrm{H}$ and ${ }^{13} \mathrm{C}$ spectra were complicated due to the formation of a diastereoisomeric mixture. ${ }^{1} \mathrm{H}$ NMR $\left(600 \mathrm{MHz}, \mathrm{CD}_{3} \mathrm{CN}\right) \mathrm{ppm} 1.80(\mathrm{~s}$, $3 \mathrm{H}), 1.80(\mathrm{~s}, 3 \mathrm{H}), 2.26-2.32(\mathrm{~m}, 4 \mathrm{H}), 2.37-2.46(\mathrm{~m}, 2 \mathrm{H}), 2.61(\mathrm{~s}, 4 \mathrm{H})$, $2.62(\mathrm{~s}, 4 \mathrm{H}), 2.75(\mathrm{t}, 2 \mathrm{H}, J=6.0 \mathrm{~Hz}), 2.77(\mathrm{t}, 2 \mathrm{H}, J=6.0 \mathrm{~Hz}), 2.77-2.84$ $(\mathrm{m}, 2 \mathrm{H}), 3.33-3.45(\mathrm{~m}, 4 \mathrm{H}), 3.75-3.79(\mathrm{~m}, 12 \mathrm{H}), 3.83(\mathrm{~s}, 3 \mathrm{H}), 3.83(\mathrm{~s}$ $3 \mathrm{H}), 4.12-4.23(\mathrm{~m}, 6 \mathrm{H}), 4.23-4.31(\mathrm{~m}, 4 \mathrm{H}), 4.32-4.40(\mathrm{~m}, 2 \mathrm{H}), 4.37(\mathrm{~s}$, 4H) $4.38(\mathrm{~s}, 4 \mathrm{H}), 5.05-5.11(\mathrm{~m}, 2 \mathrm{H}), 5.20-5.26(\mathrm{~m}, 2 \mathrm{H}), 6.10-6.19(\mathrm{~m}$, $4 \mathrm{H}), 6.82-6.92(\mathrm{~m}, 8 \mathrm{H}), 7.21-7.45(\mathrm{~m}, 26 \mathrm{H}(\mathrm{DMT} \times 18)), 7.53(\mathrm{t}, 4 \mathrm{H}$, $J=7.5 \mathrm{~Hz}$, Benzoyl), $7.64(\mathrm{t}, 2 \mathrm{H}, J=7.5 \mathrm{~Hz}$, Benzoyl), 7.92-8.00 (m, $4 \mathrm{H}$, Benzoyl), 8.07-8.15 (m, 2H), $8.49(\mathrm{~s}, 1 \mathrm{H}), 8.51(\mathrm{~s}, 1 \mathrm{H}), 9.01$ (broad s, 1H), 9.05 (broad s, 1H) 9.15 (broad s, 2H); ${ }^{13} \mathrm{C}$ NMR $(151 \mathrm{MHz}$, $\mathrm{CD}_{3} \mathrm{CN}$ ) ppm 12.7, 12.7, 20.4, 20.4, 29.5, 29.6, 29.8, 29.8, 37.1, 37.2, 37.3, 40.5-40.7, 49.6, 56.0, 63.2, 63.5, 63.6, 63.8-64.1, 68.5-68.7, 75.1, 75.2, 78.8-79.2, 83.1-83.3, 85.7-86.0, 86.0-86.2, 87.9-87.9, 88.1, 111.9, 114.3, 123.9, 124.8, 128.1 (DMT), 129.1 (DMT), 129.1 (DMT), 129.1 (Benzoyl), 129.8 (Benzoyl), 131.1 (DMT), 131.1 (DMT), 131.2 (DMT), 134.0 (Benzoyl), 136.4-136.6 (DMT), 136.7, 137.6, 137.6, 145.6 (DMT), 145.7, 151.5, 155.7 (DMT), 159.9-160.0, 172.9, 173.0; ${ }^{19} \mathrm{~F}$ NMR $\left(565 \mathrm{MHz}, \mathrm{CD}_{3} \mathrm{CN}\right) \mathrm{ppm}-117.1-(-116.1)\left(\mathrm{m}, \mathrm{PF}_{3}\right),-89.2-(-87.2)$ $\left(\mathrm{m}, \mathrm{CF}_{2} \mathrm{CF}_{3}\right),-82.7-(-80.8)\left(\mathrm{m}, \mathrm{CF}_{2} \mathrm{CF}_{3}\right),-45.8-(-43.8)\left(\mathrm{m}, \mathrm{CF}_{2} \mathrm{CF}_{3}\right) ;{ }^{31} \mathrm{P}$ NMR (243 MHz, CD ${ }_{3} \mathrm{CN}$ ) ppm -1.23, -1.08; MS (ES) Calc 1199.4127 $\left(\mathrm{M}^{+}\right)$, Found 1199.3940, Calc $444.9450\left(\mathrm{M}^{-}\right)$, Found 444.9416.

\section{Acknowledgements}

We wish to thank Prof. Colin McCoy and the late Prof. Ken Seddon for their valuable discussion and support.

\section{Conflict of Interest}

The authors declare no conflict of interest.

Keywords: DNA synthesis · mechanochemistry • ionic liquids oligonucleotides $\cdot$ soluble supports
[1] R. L. Letsinger, V. Mahadevan, J. Am. Chem. Soc. 1965, 87, 3526-3527.

[2] S. L. Beaucage, M. H. Caruthers, Tetrahedron Lett. 1981, 22, 1859-1862.

[3] L. J. McBride, M. H. Caruthers, Tetrahedron Lett. 1983, 24, 245-248.

[4] J. D. Thorpe, D. O’Reilly, T. Friščić, M. J. Damha, Chem. Eur. J. 2020, 26, 8857-8861.

[5] H.-P. Meyer, O. Werbitzky in Biocatalysis for Green Chemistry and Chemical Process Development (Eds.: J. Tao, R. Kazlauskas), John Wiley \& Sons Inc., Hoboken, New Jersey, 2011, pp. 23-43.

[6] H. Lönnberg, Beilstein J. Org. Chem. 2017, 13, 1368-1387.

[7] G. M. Bonora, Gazz. Chim. Ital. 1987, 117, 379-380.

[8] G. M. Bonora, C. L. Scremin, F. P. Colonna, A. Garbesi, Nucleic Acids Res. $1990,18,3155-3159$

[9] G. M. Bonora, G. Biancotto, M. Maffini, C. L. Scremin, Nucleic Acids Res. 1993, 21, 1213-1217.

[10] V. Kungurtsev, J. Laakkonen, A. G. Molina, P. Virta, Eur. J. Org. Chem. 2013, 2013, 6687-6693.

[11] V. Kungurtsev, P. Virta, H. Lönnberg, Eur. J. Org. Chem. 2013, 2013, 7886-7890.

[12] A. G. Molina, A. M. Jabgunde, P. Virta, H. Lönnberg, Beilstein J. Org. Chem. 2014, 10, 2279-2285.

[13] A. G. Molina, A. M. Jabgunde, P. Virta, H. Lönnberg, Curr. Org. Synth. 2015, 12, 202-207.

[14] V. Kungurtsev, H. Lönnberg, P. Virta, RSC Adv. 2016, 6, 105428-105432.

[15] A. G. Molina, V. Kungurtsev, P. Virta, H. Lönnberg, Molecules 2012, 17, $12102-12120$.

[16] M. C. de Koning, A. B. T. Ghisaidoobe, H. I. Duynstee, P. B. W. Ten Kortenaar, D. V. Filippov, G. A. van der Marel, Org. Process Res. Dev. 2006, 10, 1238-1245.

[17] S. Kim, M. Matsumoto, K. Chiba, Chem. Eur. J. 2013, 19, 8615-8620.

[18] G. M. Bonora, A. Baldan, O. Schiavon, P. Ferruti, F. M. Veronese, Tetrahedron Lett. 1996, 37, 4761-4764.

[19] K. Seddon, TCE 2002, 730, 33-35.

[20] J. Claus, F. O. Sommer, U. Kragl, Solid State lonics 2018, 314, 119-128.

[21] Q. Zeng, A. Mukherjee, P. Müller, R. D. Rogers, A. S. Myerson, Chem. Sci. 2018, 9, 1510-1520.

[22] M. Sivapragasam, M. Moniruzzaman, M. Goto, Biotechnol. J. 2016, 11, 1000-1013.

[23] C. Huo, T. H. Chan, Chem. Soc. Rev. 2010, 39, 2977-3006.

[24] W. Miao, T. H. Chan, Acc. Chem. Res. 2006, 39, 897-908.

[25] W. Miao, T.-H. Chan, J. Org. Chem. 2005, 70, 3251-3255.

[26] X. He, T. H. Chan, Synthesis 2006, 10, 1645-1651.

[27] R. A. Donga, S. M. Khaliq-Uz-Zaman, T.-H. Chan, M. J. Damha, J. Org. Chem. 2006, 71, 7907-7910.

[28] R. A. Donga, M. Hassler, T.-H. Chan, M. J. Damha, Nucleosides Nucleotides Nucleic Acids 2007, 26, 1287-1293.

[29] R. A. Donga, T.-H. Chan, M. J. Damha, Can. J. Chem. 2007, 85, 274-282.

[30] S. L. James, C. J. Adams, C. Bolm, D. Braga, P. Collier, T. Friščić, F. Grepioni, K. D. M. Harris, G. Hyett, W. Jones, A. Krebs, J. Mack, L. Maini, A. G. Orpen, I. P. Parkin, W. C. Shearouse, J. W. Steed, D. C. Waddell, Chem. Soc. Rev. 2012, 41, 413-447.

[31] G. A. Bowmaker, Chem. Commun. 2013, 49, 334-348.

[32] J.-L. Do, T. Friščić, Synlett 2017, 28, 2066-2092.

[33] E. Amigues, C. Hardacre, G. Keane, M. Migaud, M. O'Neill, Chem. Commun. 2006, 72-74.

[34] A. E. Visser, R. P. Swatloski, W. M. Reichert, S. T. Griffin, R. D. Rogers, Ind. Eng. Chem. Res. 2000, 39, 3596-3604.

[35] K. Crossey, C. Hardacre, M. E. Migaud, Chem. Commun. 2012, 48, 11969 11971.

[36] C. Hardacre, H. Huang, S. L. James, M. E. Migaud, S. E. Norman, W. R. Pitner, Chem. Commun. 2011, 47, 5846-5848.

[37] Q. Song, Y. S. Sanghvi, Nucleosides Nucleotides Nucleic Acids 2001, 20, 1267-1270.

[38] G. A. Bowmaker, J. V. Hanna, R. D. Hart, B. W. Skelton, A. H. White, Dalton Trans. 2008, 5290-5292.

[39] P. Kumar, N. N. Ghosh, K. L. Sadana, B. S. Garg, K. C. Gupta, Nucleosides Nucleotides 1993, 12, 565-584.

[40] M. R. Hassler, PhD thesis, McGill University (CA), 2013.

Manuscript received: January 9, 2021

Version of record online: 


\section{FULL PAPERS}

Mechanochemistry was explored as an alternative to solvent-based methods for oligonucleotide synthesis; first, for functionalising an ionic liquid support with a nucleoside, and second, for the coupling step of oligonucleotide synthesis. Advantages enabled by mechanochemistry are one-pot syntheses, reduced volumes of solvents, use of less toxic solvents, and avoiding the need to fully solubilise the supported-nucleoside during the coupling step.

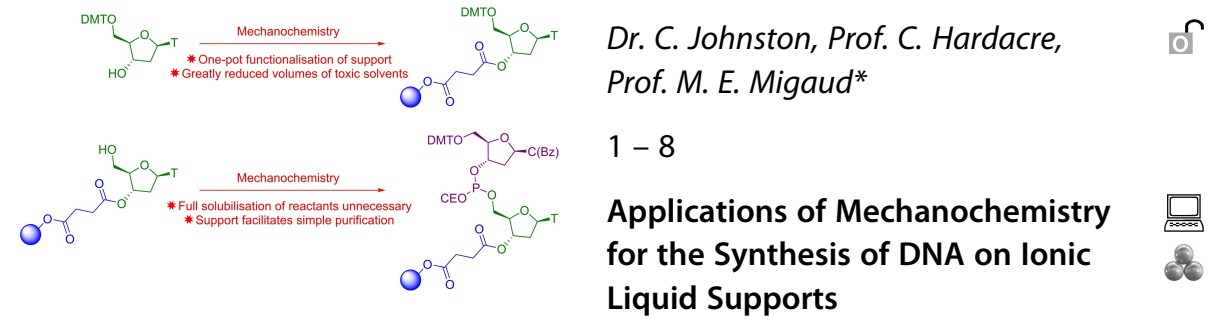

Dr. C. Johnston, Prof. C. Hardacre م for the Synthesis of DNA on Ionic 